\title{
Potencial aproveitamento de lodo de ETE na construção civil em Recife/PE
}

\begin{abstract}
A água é um dos elementos essenciais para sobrevivência e o desenvolvimento do ser humano, seu consumo está atrelado a geração de águas residuais não reaproveitáveis e tem exigido das autoridades públicas e privadas a criação de ações capazes de compatibilizar a relação existente entre desenvolvimento e as limitações da exploração da água enquanto recurso natural. Para minimizar os impactos causados pelo despejo de águas residuais na natureza foram criadas as estações de tratamento de esgoto (ETE) contudo, durante o processo de tratamento de esgotos são gerados subprodutos como o lodo, cuja disposição final é uma preocupação mundial. No estado de Pernambuco tais resíduos são dispostos em terrenos das próprias estações, e em alguns casos são dispostos nos terrenos das estações, levados por terceiros para serem utilizados como fertilizante na agricultura ou enviados à aterros sanitários para disposição final. Por conta disso, o presente trabalho busca apresentar as possibilidades de utilização de lodos de estação de tratamento de esgotos gerados na cidade do Recife e na região metropolitana para setor da construção civil. Este estudo foi realizado por meio de um levantamento bibliográfico sobre a temática de incorporação de lodos de ETE na produção de materiais aplicados a construção civil, bem como a apresentação do potencial das ETEs de Recife e entorno para a execução destes materiais. A partir dos resultados obtidos foi possível constatar que o lodo de ETE pode apresentar diversas formas de reaproveitamento e em vários setores, mas no âmbito da construção civil é comumente utilizado como matéria prima para a fabricação de cimento, argamassa, concreto, telhas, tijolos e vários tipos de pavimentos. Destaca-se, entretanto, a utilização do lodo como substituto ao cimento, visto que é mais interessante do ponto de vista econômico para obras de pavimentação de concreto, já que este tipo de obra usa elevadas quantidades de concreto empregadas em grandes extensões, promovendo, desta forma, maiores benefícios econômicos e potencialmente melhores resultados no âmbito ambiental. Sendo assim, conclui-se que a reutilização do lodo de esgoto, após o processamento adequado, em produtos para construção civil pode apresentar diversos benefícios ecológicos que justificam os custos do seu tratamento.
\end{abstract}

Palavras-chave: Águas Residuais; Esgoto; Aterros Sanitários.

\section{Potential use of WWTP sludge in civil construction in Recife/PE}

Water is one of the essential elements for human survival and development, its consumption is linked to the generation of non-reusable wastewater and has required public and private authorities to create actions capable of reconciling the relationship between development and limitations. exploitation of water as a natural resource. In order to minimize the impacts caused by the wastewater discharge in the nature, the sewage treatment plants (STS) were created, however, during the sewage treatment process, by-products such as sludge are generated, whose final disposal is a worldwide concern. In the state of Pernambuco such wastes are disposed of on the grounds of the stations themselves, and in some cases are disposed of on the grounds of the stations, taken by third parties to be used as fertilizer in agriculture sent or to landfills for final disposal. Because of this, the present work seeks to present the possibilities of using sewage treatment sludge generated in the city of Recife and in the metropolitan region for the construction sector. This study was conducted through a bibliographic survey on the theme of incorporation of STS sludge in the production of materials applied to civil construction, as well as the presentation of the potential of the STS of Recife and surrounding areas for the execution of these materials. From the results obtained it was possible to verify that the STS sludge can present various forms of reuse and in various sectors, but in the construction sector it is commonly used as raw material for the manufacture of cement, mortar, concrete, tiles, bricks and various types of floors. However, the use of sludge as a substitute for cement stands out, as it is more economically interesting for concrete paving works, as this type of work uses large amounts of concrete employed in large extensions, promoting, thus, greater economic benefits and potentially better environmental outcomes. Thus, it is concluded that the reuse of sewage sludge, after proper processing, in construction products can have several ecological benefits that justify the costs of their treatment.

Keywords: Wastewater; Sewage; Landfills.

Topic: Engenharia da Sustentabilidade e Meio Ambiente

Reviewed anonymously in the process of blind peer
Received: 12/08/2019

Approved: $27 / 09 / 2019$
Maria Angela Oliveira Mergulhão Diniz Instituto de Tecnologia de Pernambuco, Brasil http://lattes.cnpq.br/0576224182766068 mamergulhao@gmail.com

Daniele de Castro Pessoa de Melo (iD)

Instituto de Tecnologia de Pernambuco, Brasil http://lattes.cnpq.br/4010783198064867 http://orcid.org/0000-0003-4058-092X

daniele.castro@itep.br

\section{Referencing this:}

DINIZ, M. A. O. M.; MELO, D. C. P.. Potencial aproveitamento de lodo de ETE na construção civil em Recife/PE. Revista Ibero Americana de Ciências Ambientais, v.10, n.5, p.187-203, 2019. DOI: http://doi.org/10.6008/CBPC2179-6858.2019.005.0017

DOI: 10.6008/CBPC2179-6858.2019.005.0017 


\section{INTRODUÇÃO}

O aumento da população mundial e o desenvolvimento tecnológico promovem a ampliação da demanda de consumo de diversos bens e produtos (SOUZA et al., 2015). E nos últimos tempos é notório que as tecnologias rapidamente se tornam obsoletas e as demandas dos seres humanos, ainda que supérfluas, aumentem esse consumo. Além disso para atender as vontades e anseios humanos, cresce a cada dia, a pressão pela exploração de mais recursos naturais, aumentando a demanda por matéria prima, gerando resíduos dos mais diversos e impactando o meio ambiente de forma negativa.

A água, por exemplo, é um dos elementos essenciais para sobrevivência e o desenvolvimento do ser humano em diversas atividades. Seu consumo está atrelado a geração de águas residuais não reaproveitáveis para fins potáveis, poluindo os ecossistemas e causando desequilíbrios ecológicos. Isso tem exigido das autoridades públicas e privadas a criação de ações capazes de compatibilizar a relação existente entre desenvolvimento e as limitações da exploração da água enquanto recurso natural (REBOUÇAS et al., 2017).

Para minimizar os impactos causados pelo despejo de águas residuais na natureza foram criadas as Estações de Tratamento de Esgoto (ETE), que buscam minimizar os impactos na devolução de águas residuais ao meio ambiente. O método, que de modo geral é utilizado pelas estações de tratamento no Brasil é denominado 'método de lodos ativados'. Foi desenvolvido na Inglaterra e consiste num sistema em que uma massa biológica cresce e forma flocos, que são recirculados e colocados em contato com a matéria orgânica num ambiente aeróbico, caracterizado pela apresentação de duas fases, uma líquida e outra sólida (OLIVEIRA et al., 2016). Contudo, durante este processamento são geradas grandes quantidades de lodos, que são resíduos que podem caracterizados por conter em sua composição cerca de $30 \%$ de matéria mineral e $70 \%$ de matéria orgânica, biodegradáveis e inertes, que serão separadas ao longo do processo de tratamento dos esgotos. Ao longo da digestão o lodo perde cerca de $2 / 3$ de matéria orgânica, apresentando após a digestão 45\% de matéria orgânica e 55\% de substâncias minerais (MATOS et al., 2017).

Mas a questão que de modo geral demanda uma preocupação é o fato da disposição final deste resíduo, dado que são geradas grandes quantidades que, quando não manejado de forma adequada, pode comprometer até $50 \%$ do orçamento operacional de um sistema de tratamento e ainda apresentarem elevado potencial de carga poluidora, capaz de gerar sérios problemas socioambientais (VISENTIN et al., 2017). Independente da origem e finalidade, o lodo deve ser tratado tanto para reduzir seu volume e quantidade de água, quanto para garantir a estabilização da matéria orgânica e evitar problemas ambientais futuros com o não aproveitamento ou disposição final inadequada deste subproduto (MOREIRA et al., 2019).

No estado de Pernambuco os resíduos primários gerados nas estações de tratamento de esgoto são dispostos, em sua maioria, em terrenos das próprias estações, e em alguns casos, enviados a aterros sanitários para disposição final. Enquanto os lodos do tratamento secundário, após passarem por processos de estabilização, são dispostos nos terrenos das estações ou levados por terceiros para serem utilizados como fertilizante na agricultura (ARAUJO et al., 2018).

Entretanto, os lodos gerados nas estações de tratamento de esgoto apresentam características 
distintas que são determinadas a partir das atividades realizadas em cada região. Estes resíduos apresentam um elevado potencial de reaproveitamento, que vão desde usos no setor da construção civil à recuperação de áreas degradadas e melhoramento dos solos para a agricultura.

Por conta da gama de possibilidades atreladas ao lodo, é de suma importância determinar e entender as características do lodo, que variam de acordo com a região e o tipo de resíduos que é formado, e indicar possíveis reaproveitamentos e utilidades para o mesmo. Estudos recentes evidenciaram que o lodo de estações de tratamento de esgoto pode ser utilizado na construção civil para produção de blocos cerâmicos, de concreto asfáltico, concretos convencionais e muitos outros produtos (DUTRA et al., 2015; LUCENA et al., 2017; MELLER et al., 2017).

É diante deste cenário que se torna de suma importância o desenvolvimento de locais ou estratégias de descarte ecologicamente corretas e seguras, com baixos custos de investimento e resultados significativos. E por conta disso, o presente trabalho buscou apresentar as possibilidades de utilização de lodos de estação de tratamento de esgotos gerados na cidade do Recife e na região metropolitana no setor da construção civil a partir da literatura existente.

\section{METODOLOGIA}

Esta pesquisa foi classificada como qualitativa, uma vez que possibilitou uma maior compreensão dos fenômenos envolvidos na pesquisa e considerando a importância que os outros dão às práticas (BAUER et al., 2017). A pesquisa qualitativa é extremamente importante interpretar os fenômenos e atribuir a eles significados. Não se pode separar o mundo objetivo, real, da subjetividade do sujeito, e por conta disso, a pesquisa qualitativa não é vazia, mas coerente, lógica e consistente, porque tem como base a percepção de um fenômeno num contexto. Assim, acredita-se que a pesquisa qualitativa representa uma abordagem mais completa para compreender a significação das inovações e aplicabilidades de lodos de ETE.

Por se tratar de uma análise de caráter multidisciplinar, conforme descrito por esta temática, adentra em diferentes áreas de estudo, mas de modo geral, a linguagem utilizada e a principal bibliografia relacionamse prioritariamente à área das Ciências dos Materiais (CAMPODONIO JUNIOR et al., 2014).

Quanto a classificação da natureza do objetivo, este trabalho foi descrito como de caráter descritivoexploratório. Segundo Aragão (2013), estudos descritivos têm a finalidade de descrever as principais características de determinada população e fenômenos e, em alguns casos, apresenta a possibilidade de estabelecimento de relações entre variáveis estudadas. $O$ aspecto descritivo do trabalho também pode ser explicado pela adoção de um levantamento bibliográfico, seguido pelo desenvolvimento de uma análise crítica sobre a importância incorporação de lodos de ETE no desenvolvimento de materiais aplicados à construção civil como estratégia de desenvolvimento ambiental sustentável.

Para desenvolver este trabalho, realizou-se inicialmente uma pesquisa exploratória, visto que o tema abordado pode ser abordado de diversas formas no meio acadêmico. De acordo com Gil et al. (2015), a pesquisa exploratória é utilizada quando, a 'priori', se tem uma noção muito vaga do tema de pesquisa, e diante do levantamento exploratório é possível constatar o desenvolvimento de um maior conhecimento e 
o estabelecimento de temáticas que venham a ser prioritárias para atingir o objetivo proposto.

A estratégia de pesquisa utilizada neste trabalho foi a pesquisa bibliográfica, e Pádua (2019) afirma que a pesquisa bibliográfica tem por objetivo principal recolher, selecionar, analisar e interpretar as contribuições teóricas já existentes sobre determinado assunto, e que a partir desta ótica, procura explicar ou discutir um determinado assunto, formando, desta forma, a plataforma teórica do trabalho. Para tanto, utiliza-se de referências publicadas em livros, periódicos, revistas etc. Quanto à abordagem do problema, a pesquisa se classifica como qualitativa porque se importa com aspectos que não podem ser quantificados, mas que são de suma importância para a compreensão da temática proposta.

Para cumprir esta demanda, este estudo foi realizado a partir do estudo de obras de outros autores, em seguida realizou-se a compilação de propostas para utilização de lodo de ETE's como matéria prima a ser utilizada nas seguintes áreas: cimento, argamassa, pavimentação, tijolos, telhas e pavimentos. Em seguida se apresentou de qual forma este tipo de resíduo pode ser aproveitado na região de Recife/PE a partir de pesquisas realizadas anteriormente.

\section{DISCUSSÃO TEÓRICA}

\section{Possibilidades de Utilização de Lodo de ETE}

Estratégias de reciclagem e reuso de resíduos têm sido procurados como formas de resolver os problemas criados pelas limitações em se dar um destino adequado aos resíduos sólidos ou a efluentes líquidos. As cobranças sociais estão voltadas para que estes resíduos gerados possam ser utilizados em atividades que tragam retornos ambientais e financeiros.

Como dito anteriormente, o lodo apresenta características diversas que são determinadas de acordo com o material formador do esgoto, que varia de uma região para outra por exemplo. Por apresentar características diversas, este pode ser aplicado para os mais diversos usos, que vão desde a melhoria da qualidade química de solos para a agricultura e florestas, até a composição de materiais para a construção civil (ROSA et al., 2015).

\section{Construção Civil}

A construção civil é um setor importante do país, apesar de estar em queda por conta da crise que assola o país nos últimos anos. Tal setor apresenta uma demanda diversificada de bens e serviços, e por conta disso movimenta bilhões anualmente. Baseado nas preocupações ambientais crescentes, e nas características dos lodos gerados nas estações de tratamentos de esgoto, buscam-se estratégias de utilização deste produto, ao mesmo tempo em que garanta a diminuição dos gastos com os materiais da construção civil e a garantia de qualidade do produto final. Para tanto, o lodo gerado pode ser utilizado de diversas formas, como: Agregados para construção civil - o processo de sinterização do lodo de esgoto na forma de biossólido proveniente da digestão anaeróbia gera o agregado leve, que é utilizado na fabricação de placas pré-moldadas para a construção de armários, pisos de concreto e blocos de concreto. Em alguns casos os 
agregados são produzidos a partir das cinzas do lodo, gerando, nesse caso, os agregados miúdos (SILVA et al., 2017); Fabricação de tijolos: O uso do lodo na produção de cerâmica tem sido considerado por diversos pesquisadores muito semelhante à das argilas comumente utilizadas nessa atividade. Estudos realizados na Califórnia, demostram a possibilidade de misturar $90 \%$ do lodo decorrente de processo de coagulação com sulfato de alumínio com $10 \%$ de argila para produzir um tijolo. Teixeira (2006) estudou a incorporação do lodo gerado pela ETA (Estação de Tratamento de Água) de Presidente Prudente (SP) e concluiu que é possível adicionar até $10 \%$ do lodo da ETA quando o coagulante utilizado é o sulfato de alumínio e $20 \%$ do lodo da ETA no caso do cloreto férrico. Quando utilizados em adição aos concretos ou materiais cimentantes, a fixação dos lodos ocorre por processos químicos onde os resíduos supostamente reagem com os materiais, e os compostos não reagentes são encapsulados pela matriz formada; Fabricação de material cerâmico acredita-se que os primeiros estudos para a utilização de lodos de ETEs como subproduto na engenharia civil foram como insumo para a produção de material cerâmico. Segundo estudos realizados pela Associação das Cerâmicas Vermelhas de Itu e Região, a adição de $10 \%$ de lodo em substituição à argila não altera significativamente as características do material final em relação ao produto obtido pelos processos convencionais (AREIAS et al., 2018); Produção de cimento - a indústria do cimento é responsável por cerca de $7 \%$ da emissão de gás carbônico $\left(\mathrm{CO}_{2}\right)$ na atmosfera. Para cada tonelada de cimento produzida, 0,6 tonelada de $\mathrm{CO}_{2}$ é lançada na atmosfera, e a utilização do lodo de ETEs, juntamente com resíduos industriais ou agrícolas, proporcionam uma redução de 10 milhões de toneladas de $\mathrm{CO}_{2}$, por ano, liberadas na atmosfera (GODOY, 2013).

\section{Uso Agrícolas e Florestais}

O interesse do uso de lodo de esgoto como fertilizante decorre por vários motivos, dentre eles se destaca a composição nutricional rica em nitrogênio e fósforo, além da presença de micronutrientes e elevado teor de matéria orgânica. Todos esses fatores são essenciais para o desenvolvimento vegetal, e a aplicação do lodo ao solo minimiza os gastos com fertilizantes. Pois o sistema solo-planta quando manejado adequadamente, promove a absorção e 'retenção' dos constituintes dos efluentes pela incorporação dos elementos na massa seca das plantas, resultando em diminuição na concentração de elementos nas águas subterrâneas e superficiais.

No que diz respeito à melhoria das condições físicas do solo, o lodo aumenta a retenção de água em solos arenosos e melhora a permeabilidade e infiltração nos solos argilosos e, por conseguinte, estrutura e estabiliza os agregados na superfície dos solos. A reciclagem do lodo de esgoto para uso agrícola alia baixo custo e geração de impacto ambiental positivo, entretanto, ressalta-se a necessidade de que as técnicas realizadas estejam de acordo com os critérios adequados, pois o uso inadequado pode gerar prejuízos inestimáveis ao meio ambiente (OLIVEIRA, 2017). Por conta disso, afirma-se que a eficiência econômica do processo, a segurança, a saúde e o meio ambiente são variáveis interdependentes das quais depende o sucesso da proposta.

No Brasil, o uso agrícola de lodo é uma prática pouco utilizada, apesar de diversos trabalhos 
demonstrarem efeitos positivos com o uso do lodo, como o aumento de produtividade das culturas. Para a cultura do milho, Silva et al. (2000) demonstraram que o lodo de esgoto, apresenta potencial para substituição dos fertilizantes minerais. Bettiol et al. (2000) relatam a importância do aproveitamento do lodo de esgoto para melhorar o desempenho de plantios de arroz, aveia, trigo, pastagens, feijão, soja, girassol, café e pêssego.

Apesar da comprovação de bons resultados nos experimentos citados, muitos cientistas temem que o uso inadequado do lodo possibilite a contaminação de lençóis freáticos e cursos de água, causando problemas de saúde no homem e nos animais que a consomem. Nos últimos anos técnicas de fertirrigação e hidroponia vem dando espaço para a utilização de materiais alternativos, e o lodo de ETE vem sendo bastante visado nesta perspectiva.

\section{Uso Energético}

Vários tipos de resíduo podem ser transformados em biogás, que é uma mistura gasosa produzida por digestão anaeróbia, a partir de dejetos animais, lixo orgânico doméstico, resíduos agrícolas, efluentes industriais, plantas aquáticas e o lodo de esgoto. O lodo pode ser usado como combustível pela produção de biogás, e quando produzido de forma adequada não produz gases tóxicos durante a queima, além de ser capaz de aproveitar diversos tipos de lixo orgânico, e o resíduo proveniente da utilização desta técnica também pode ser reutilizado, pois é classificado como um biofertilizante poderoso.

No Brasil, o interesse pelo biogás surgiu nas décadas de 1970 e 1980, quando programas governamentais estimularam a implantação de vários biodigestores para produção de energia térmica para substituição da lenha. E muitos produtores viram esta técnica como uma alternativa bastante viável, pois diminuem os custos de produção energéticas ao mesmo tempo em que diminui a poluição causada pelos dejetos animais e promove o aumento da renda dos criadores. Entretanto, esta metodologia não foi adiante no país por questões burocráticas, técnicas e falta de estímulo aos produtores que aderiam a esta metodologia. Apesar de não ter se desenvolvida fortemente no Brasil, a utilização do biogás para geração de energia elétrica é uma solução que reduz os níveis de emissões de gases tóxicos prejudiciais ao meio ambiente como o metano, e reduz a demanda por recursos naturais esgotáveis, como o gás natural.

\section{Reaproveitamento de lodo de ETE na Construção Civil}

A necessidade pelo desenvolvimento de propostas alternativas para a carga sólida gerada em diversas ETE's é constantemente reforçada pela fragilidade dos diversos ecossistemas regionais e suas respectivas demandas, e por conta disso, o desenvolvimento de estratégias desta magnitude deve estar atrelado a oferta de benefícios que garantam a sustentabilidade da ETE ao mesmo tempo que atendam as demandas apresentadas pela legislação ambiental.

É possível notar que nos últimos anos diversos setores da sociedade têm dado mais importância ao meio ambiente, e investindo em alternativas para a sua preservação e recuperação. No meio científico por exemplo, as discussões estão relacionas ao desenvolvimento sustentável nas mais diversas áreas do 
conhecimento, e diante desta nova perspectiva de mercado, a engenharia e seu leque de aplicações não poderia ficar de fora. E atualmente busca incorporar resíduos de outras atividades no desenvolvimento de produtos necessários ao dia a dia.

A indústria da construção civil é uma das que mais se destacam na incorporação de materiais que seriam descartados, visto que este ramo possui uma demanda elevada de produtos. No caso do gerenciamento de ETE's por exemplo, o lodo gerado no tratamento de esgotos pode representar até $60 \%$ dos custos operacionais das ETE's (GODOY, 2013), visto que estes são resíduos com elevado potencial poluidor e exigem a adoção de estratégias de disposição e reutilização segura. Por conta disso é de suma importância a adoção de alternativas que causem o menor impacto possível associado e ainda seja capaz de apresentar custos atrativos.

Na Alemanha dos anos 90, pequenas ETE's armazenavam o lodo gerado em tanques até que os fazendeiros de regiões próximas fossem buscá-lo para aplicação em solos agrícolas. Contudo, o desinteresse por parte dos fazendeiros obrigou a realização da desidratação mecânica do lodo (GODOY, 2013). Este tipo de comportamento da Alemanha de 1993 ainda é comumente encontrado no Brasil dos dias atuais.

A maior experiência brasileira de reuso de produtos gerados por indústrias na produção de materiais de construção civil é conduzida pela indústria cimenteira, que recicla uma parte das escórias de alto-forno e cinzas volantes. Pesquisas estimam que a indústria cimenteira brasileira ao adotar a reciclagem maciça de cinzas volantes ou escórias granuladas reduziu a geração de $\mathrm{CO}_{2}$ em $29 \%$ e obteve uma economia de combustível de 28\% (MATOS et al., 2019).

Diversos estudos apontam que a utilização de resíduos além de ecologicamente adequada, ainda promove a melhoria da qualidade dos materiais utilizados pela indústria da construção civil. Nos estudos desenvolvidos por Andrade (2016), por exemplo, o autor recomenda que o uso de materiais de construção produzidos com o lodo é mais viável para ambientes internos, porque os produtos contendo lodo na fabricação têm uma maior capacidade de absorção da água, o que inviabiliza o uso em construções externas, exposta às intempéries.

A incorporação do lodo de esgotos na fabricação de produtos cerâmicos, como telhas, tubos, tijolos e lajotas, é vista como uma alternativa viável de destinação adequada e sustentável, pois o lodo é adicionado ao processo durante o preparo da massa cerâmica de modo que contribua para a melhoria das características físicas do material a ser desenvolvido (SILVA, 2017).

Diante do exposto, neste trabalho serão apresentadas diversas alternativas de reaproveitamento de lodo de ETE para o ramo da construção civil. Estas alternativas apresentadas denotam o estado da arte dos estudos de desenvolvimento de materiais sustentável, ao mesmo tempo que apresentam as características e potenciais de utilização de resíduos em diversos ramos da indústria da construção civil.

\section{Produção de Cimento, Argamassa e Concreto}

Pesquisas demonstram que é possível utilizar o lodo de esgoto como substituto a agregados leves na fabricação de cimentos e concretos, bem como peças feitas desses materiais (FONTES et al., 2016). Adicionar 
cinzas do lodo ao processo produtor de cimento reduz o custo de produção e, como o cimento é o componente mais caro do concreto, ainda reduz os custos deste item indispensável na construção civil. É possível substituir 35\% do consumo de cimento 'Portland' por lodo calcinado entre temperaturas de 700 으 a 800 ㄷ (GODOY, 2013).

Infelizmente a técnica de adicionar lodo de esgoto na fabricação de cimento ainda não é vista como uma possibilidade viável em todo o país, mas nos Estados Unidos, essa operação é realizada com frequência por diversas empresas de saneamento. E não é apenas nos Estados Unidos que esta técnica é empregada, em Cingapura, cinzas do lodo de esgoto adicionadas à massa asfáltica foram utilizadas com sucesso na construção de estradas (FONTES et al., 2016).

Tay et al. (2002) testaram lodo digerido e desidratado com cal, para criar um cimento biológico, denominado 'Bio-cimento'. Ao substituírem o usual cimento Portland por este novo produto para produção de argamassa, os autores puderam verificar que adições de até 10\% proporcionaram resistência ligeiramente superior à encontrada na convencional, mas, para valores de até $30 \%$ a resistência ficou próxima da argamassa padrão.

Em 2005, Lessa utilizou o lodo gerado em estação de tratamento de esgoto misto como adição em argamassa da construção civil, depois de incinerado, e observou em ensaios de até 20\% de lodo incinerado, que quanto maior a adição, maior a resistência à compressão. Silveira et al. (2009) estudaram a substituição parcial do cimento 'Portland' por cinzas de lodo de esgoto. Os autores constataram que as resistências à compressão das argamassas produzidas com substituição de $10 \%$, 20\% e $30 \%$ do cimento 'Portland' por cinza foram semelhantes aos valores apresentados com a utilização de argamassa padrão, e quanto à resistência à tração por compressão diametral, os autores concluem afirmando que não houve alteração significativa entre as argamassas. Queiroz et al. (2019) utilizaram Cinza de lodo de esgoto com resíduo sólido urbano para produzir um tipo de concreto e concluíram que tanto a incorporação de cinza de lodo como a de cinza de resíduo sólido urbano mostraram-se uma alternativa viável do ponto de vista técnico e ambiental (Figura 1).

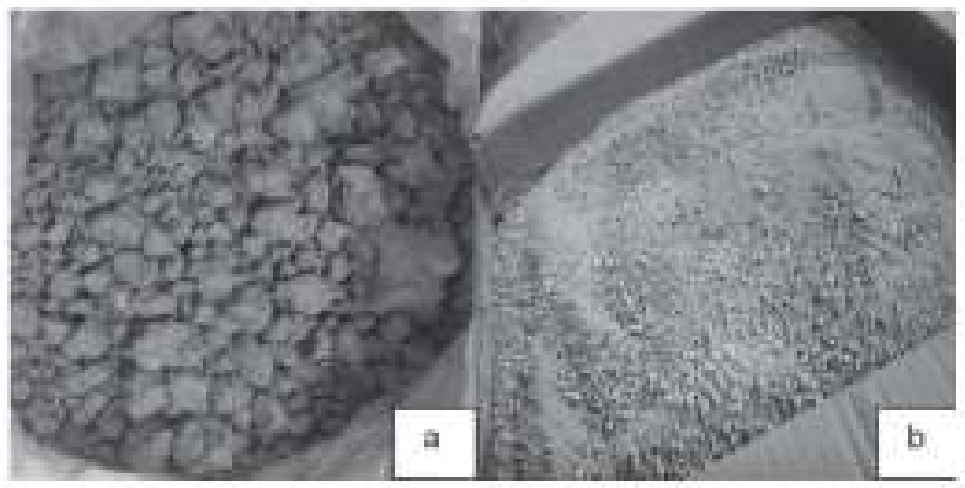

Figura 1: Lodo de ETE incorporado para a fabricação de cimento. Fonte: Azevedo et al. (2017).

Ou seja, diversos pesquisadores realizaram experimentos de cinza de lodo de esgoto misturada com argamassa e abriram caminhos para novos trabalhos no mesmo tema. Mas uma coisa é certa, existe a possibilidade de se utilizar argamassa contendo adição de cinza de lodo e as propriedades necessárias para a argamassa podem ser alcançadas, mesmo que a qualidade seja menor do que a da argamassa sem lodo de 
esgoto (COSTA, 2014). Ainda é possível indicar que os benefícios de engenharia permitem a melhoria das propriedades estruturais dos concretos no que diz respeito à trabalhabilidade, ganho de resistência, durabilidade ao ataque químico.

Benefício econômico da incorporação de lodo de ETE se faz claro na redução do uso de cimento, que é o material de maior custo presente na constituição do concreto. Enquanto benefícios ecológicos são obtidos quando são apresentadas estratégias de destinação adequada para este tipo de resíduos, que muitas vezes contem grande carga de metais pesados e substâncias tóxicas, deixando de ser depositados em aterros e não mais contaminando o solo e águas subterrâneas.

\section{Produção de Tijolos e Telhas}

A indústria cerâmica é uma das que mais se destacam na reciclagem de resíduos industriais e urbanos, porque além de apresentar elevado volume de produção, ainda possui características físicoquímicas favoráveis a incorporação de novas substancias (FONSECA et al., 2018). Além disso, a incorporação de resíduos na matriz cerâmica traz diversas vantagens (Figura 2) para a indústria, como economia de matéria-prima não-renovável, obtenção de produtos com forte apelo ambiental, redução do consumo de energia e outros (PIRES et al., 2012).

Baseado nesta gama de características que possibilitam a incorporação de novos materiais nestes produtos, Areias et al. (2018) avaliaram a adição do lodo de ETE para a fabricação de materiais de construção e a partir de diversos ensaios concluíram que de fato é possível a utilização dos lodos de águas residuais para a fabricação de materiais de construção (cerâmica vermelha), desde que se utilize a proporção adequada de argila-lodo e argilas de natureza adequada e se aplique o tratamento térmico apropriado.

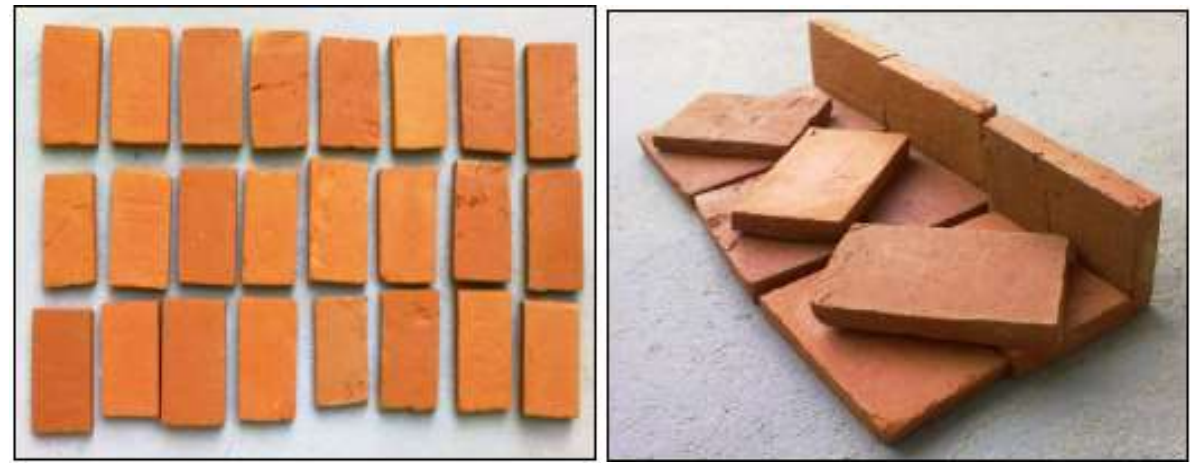

Figura 2: Tijolos fabricados com lodos de ETE. Fonte: Pires et al. (2012).

Rodrigues et al. (2013) avaliaram a possibilidade de incorporação de lodo de ETE na fabricação de tijolo solo-cimento para uso na construção civil e verificaram que o lodo aumenta o teor de partículas finas, matéria orgânica e plasticidade da mistura solo-cimento. Diversos estudos revelam que dependendo da proporção da adição do lodo, as características físicas e mecânicas de uma massa cerâmica podem ser comprometidas, no entanto, a fração pode ser aumentada desde que seja realizado o beneficiamento do lodo por calcinação e moagem, diminuindo assim o efeito negativo das partículas do lodo na resistência mecânica (AREIAS et al., 2018). 
Siqueira Junior (2011), ao analisar a viabilidade da incorporação do lodo para fabricação de tijolo vermelho verificou que o lodo é um composto que otimiza as propriedades mecânicas e físicas dos materiais cerâmicos, tornando-o um grande potencial para aproveitamento na indústria de tijolos cerâmicos, no entanto, existe a necessidade de utilizar processos que eliminem o material orgânico contido no lodo. Por conta disso acredita-se que a efetiva utilização do lodo para a produção de cerâmica vermelha estará atrelada à aceitação e ao custo por parte das indústrias cerâmicas e consumidores finais. Visto que, o custo será influenciado pelas condições em que a matéria prima será obtida e pelas facilidades ofertadas pela companhia de saneamento.

\section{Produção de Pavimentos}

Pavimento pode ser descrito como a superestrutura constituída por uma combinação de camadas finitas, assentes sobre um terreno ou fundação o qual é designado subleito (CAVALCANTI et al., 2019). Esta atividade da engenharia civil consome uma grande quantidade de recursos, a ponto que o emprego de resíduos pode ser vantajoso, pois pode poupar recursos e matéria prima, unindo a economia com o descarte adequado e o benefício da obra.

A construção de rodovias vem sendo vista como uma das melhores estratégias para aplicação de resíduos, pois nesta atividade existe a capacidade de permissão de um certo encapsulamento, e mesmo a contenção de metais ou outros poluentes, por combinação com outros materiais usuais de construção das camadas do pavimento. Tanto que alguns estudiosos brasileiros utilizaram resíduo de lodo de esgoto na pavimentação, tais como Lucena et al. (2016), obtendo resultados mecânicos, ambientais e econômicos satisfatórios.

Resíduos podem ser aplicados na pavimentação, desde que o seu reaproveitamento não traga nenhuma perda das propriedades do pavimento, e que o desempenho do mesmo não seja comprometido. Mas vale ressaltar que esta possibilidade somente deve ser concebida após ensaios que comprovem sua viabilidade quanto às propriedades de engenharia como: resistência, durabilidade, impacto ambiental gerado com o seu uso e estudos de lixiviação, dentre outros. Algumas das investigações para viabilidade da utilização dos resíduos são verificar a minimização dos impactos ambientais por meio da redução de emissões de fumaça, entulhos, odores dentre outros benefícios que justifiquem o uso.

Medeiros (2006) usou lodo de uma ETE em Natal, no Rio Grande do Norte, que passou na peneira №. 200 e após ser seca em estufa e calcinada a uma temperatura de 900 드 durante 3 horas em mufla, foi usada como 'filler', material de enchimento em concreto asfáltico. Comparou o uso de cimento como 'filler' e o lodo calcinado em substituição ao cimento nas proporções de $1 \%, 2 \%$ e $3 \%$. Concluiu que as misturas com lodo calcinado e com o cimento apresentaram idêntico comportamento mecânico, atendendo as especificações do DNIT (Departamento Nacional de Infraestrutura de Transportes). A mistura com 1\% de lodo calcinado apresentou melhor desempenho volumétrico e mecânico.

Macedo et al. (2006), em sua pesquisa com estudos alternativos do aproveitamento do lodo de esgoto, analisou o uso de lodo tratado de uma (ETE) para melhoramento de um solo colapsível e pôde 
observar que os lodos não podem ser considerados como um resíduo único, pois constituem uma família diferente de lodos de diferentes tipos de ETE, mas concluiu que o lodo mostrou-se adequado para melhoramento de solos colapsíveis.

Em se tratando de resistência a compressão, para construção de calçadas, Gasparim (2015), submeteu corpos de prova, conforme a NBR-12118 (Blocos vazados de concreto simples para alvenaria), os quais os resultados encontrados forma superiores aos exigidos pela norma NBR-6136 12118 (Blocos vazados de concreto simples para alvenaria estrutural). Nestes, para os ensaios, foram adicionados $50 \%$ de areia de ETE, no lugar de agregado convencional, e $10 \%$ de lodo e $50 \%$ de areia de ETE, no lugar de agregado convencional, e $15 \%$ de lodo (Figura 3).

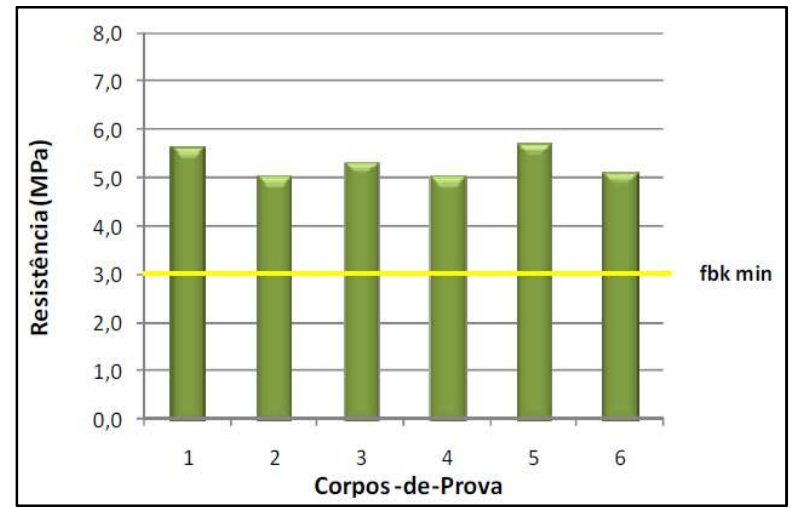

Figura 3: Agregado 50\% areia de ETE e 10\% de lodo. Fonte: Gasparim (2013)

Já na questão do ensaio de absorção de água por capilaridade, uma vez que o ingresso mais frequente de agentes agressivos (íons cloreto e $\mathrm{CO}_{2}$ ) no concreto é por meio de sua rede de poros, Ramiez (2015) verificou que a absorção de água aumentou com o incremento na quantidade de lodo úmido e calcinado (Figura 4).

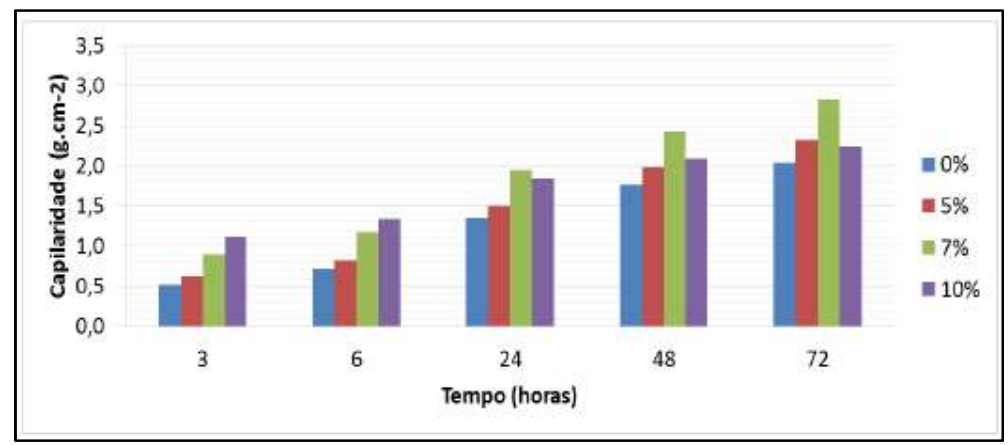

Figuras 4: Ensaio de absroção de água por capilaridade. Fonte: Ramirez (2015).

Com o aumento da absorção, o autor indica que ouve a redução dos poros e consequentemente promoveria uma maior subida de água por capilaridade, que foi comprovada 72 horas depois com a aferição da altura de absorção de cada corpo de prova, que foram rompidos por compressão diametral (Figura 5). 


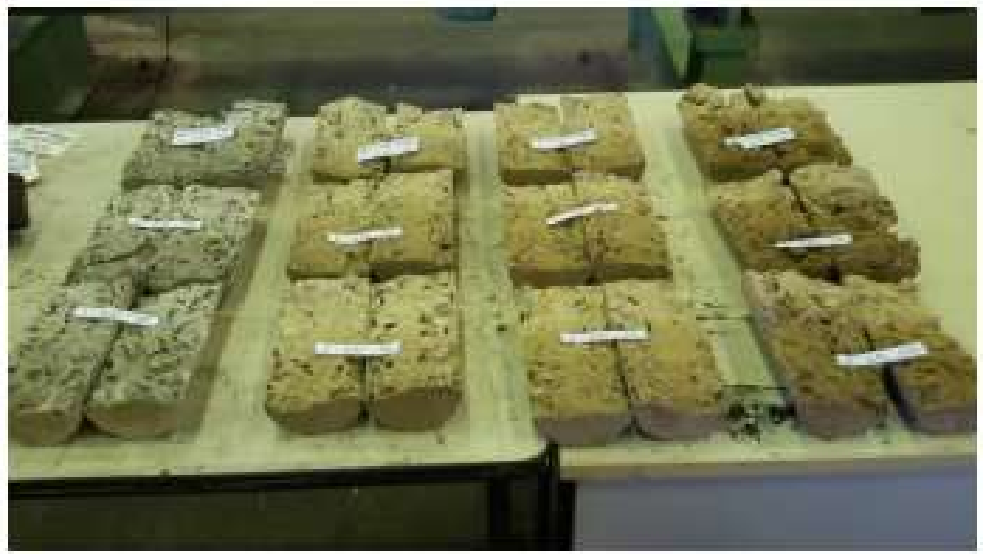

Figura 5: Ensaio de absroção de água por capilaridade - corpos de prova. Fonte: Ramirez (2015).

\section{Estações de tratamento de esgoto (ETE) em Recife e Região Metropolitana}

Já é sabido que ETE's são unidades onde o esgoto, após sair das nossas residências e passar pela rede coletora é levado para ser tratado antes de ser devolvido ao meio-ambiente, lançados em rios, lagos ou no mar. Que, antes de ser devolvido ao meio ambiente, este esgoto passa por diversos tipos de tratamentos, que podem ser físicos, químicos e biológicos (KUMMROW et al., 2015).

A rede de esgoto é um sistema fechado e operado, que no estado de Pernambuco é formado por tubos de cerâmica ou PVC (Policloreto de Vinila) com diâmetro de $15 \mathrm{~cm}$, que coletam o esgoto nas casas e o transportam para uma estação de tratamento. No estado de Pernambuco, a empresa responsável tanto pelo abastecimento de água quanto pelo tratamento de efluentes é a Companhia Pernambucana de Saneamento - COMPESA, que conta com algumas técnicas de tratamento de esgoto em suas ETE's, tais como: Decantador, UASB (Upflow Anaerobic Sludge Blanket), Tanque Imhoff, Lagoa de Estabilização, Lodo Ativado com Aeração Prolongada, Valo de Oxidação e Biofiltro (COMPESA, 2018).

Na região de Recife e zona metropolitana a COMPESA atende as cidades do Recife, Cabo, Jaboatão, Olinda, Paulista, Abreu e Lima e São Lorenzo da Mata. Mas para atender toda esta população, apenas na Região Metropolitana do Recife são aproximadamente 30 estações de tratamento de esgoto, em que as maiores são a ETE-Cabanga, ETE-Peixinhos e ETE-Janga.

A ETE-Cabanga foi a primeira a entrar em operação no Recife e atualmente o complexo tem capacidade de tratamento de 925 litros de esgoto por segundo, por meio de decantadores e biodigestores. Seu sistema é composto por uma rede coletora com 214 km de extensão, 17 estações elevatórias e uma Estação de Tratamento que abrange uma área de aproximadamente 1.718 hectares (COMPESA, 2018), que atende cerca de 176.670 habitantes e todo efluente tratado da ETE Cabanga é lançado no Rio Jiquiá (SILVA et al., 2011).

A estação Peixinhos está localizada na Rua Nova Esperança, na cidade de Olinda - PE e iniciou seus trabalhos no ano de 1972. Foi projetada para receber parte dos efluentes originários nos bairros de Casa Forte, Casa Amarela, Parnamirim, Beberibe e outros bairros de Recife, também recebe efluentes de conjuntos habitacionais como Ignez Andreazza e Cajueiro, e parte dos efluentes gerados em Olinda. Em 2011, atendia a uma população de aproximadamente 314.500 habitantes (SILVA, 2001), com capacidade para 
tratar $36.000 \mathrm{~m}^{3} /$ dia de esgoto, com uma vazão média de $18.000 \mathrm{~m}^{3} /$ dia. O Sistema de Esgotamento Sanitário Peixinhos é composto por uma rede coletora de aproximadamente $109 \mathrm{~km}$ de extensão, 13 estações elevatórias de esgotos e uma Estação de Tratamento, localizada em Olinda (COMPESA, 2018). O tratamento utilizado nesta estação de tratamento vai até o tipo secundário e faz uso do processo de filtração biológica. Após o tratamento realizado na estação Peixinhos, os efluentes tratados são lançados no rio Beberibe (SILVA et al., 2008).

A ETE Janga foi projetada para atender 451.900 habitantes e encontra-se localizada próximo a PE-22, em Paulista, e lança seu efluente tratado no Rio Timbó. Mas além desses sistemas, Recife conta com um conjunto de outras 18 pequenas estações de tratamento operando e com capacidade total de 302 litros por segundo.

Outra ETE importante é a Estação de Tratamento Dancing Days, que está localizada na Rua Nossa Senhora do Carmo, bairro da Imbiribeira, na cidade do Recife/PE. A ETE foi projetada para receber e tratar esgoto doméstico, afim de atender cerca de 60.000 habitantes, entretanto, é possível que atualmente a ETE atenda até 90.000 habitantes, apresentando uma vazão média de 240L/s. A estação de tratamento Dancing Days possibilita que o esgoto seja tratado desde o processo preliminar até o terciário, e desta forma garante que os efluentes sejam tratados adequadamente para serem devolvidos ao meio ambiente causando prejuízos mínimos aos ecossistemas receptores.

\section{Potencial de utilização de lodo de ETE em Recife e Região Metropolitana}

Implantar uma Unidade de Gerenciamento de Lodo (UGL) em uma ETE requer que sejam realizados diversos estudos referentes à estrutura física e à capacidade operacional, levando em consideração o tipo de destinação final escolhida (GODOY, 2013). Pois as características dos efluentes recebidos influenciarão diretamente nas etapas de tratamento necessárias e, consequentemente, na quantidade e na qualidade de lodo gerado.

A viabilidade técnica do gerenciamento do lodo depende da análise de diversos fatores como: áreas disponíveis (para processamento e aplicação), instalações existentes e adequações necessárias, tipo de transporte e manuseio, existência de mão de obra especializada ou treinada e a gestão e controle da UGL (SILVA et al., 2018). Pois é importante ressaltar que é a partir destas características que é possível determinar quais as propriedades ou possíveis usos potenciais de lodo de uma dada ETE.

Se a reciclagem agrícola, que é a finalidade mais comum e barata atualmente for a destinação final escolhida, será preciso definir o local onde o lodo será aplicado, além de entender quais as áreas de influência desta área que recebera este biossólido, pois a distância entre a ETE e a área agrícola onde o lodo será aplicado é fator determinante no custo da operação e o teor de sólidos determinará o tipo de transporte mais adequado, além de ser o ponto chave para o desenvolvimento das estratégias de transporte mais adequadas.

Após a realização da análise de viabilidade técnica e por conseguinte a definição dos possíveis usos alternativos, é possível realizar a análise de viabilidade econômica. Nesta etapa serão definidos os critérios 
de aproveitamento e adaptação dos materiais, instalações e equipamentos já existentes para que os custos com novas aquisições ou construções sejam minimizados. Alguns equipamentos e materiais de manuseio necessários para o gerenciamento do lodo já estão presentes nas Estações de Tratamento de Esgotos convencionais. Em seguida torna-se de suma importância a realização de uma análise de logística de produção e escoamento do produto (SILVA et al., 2018).

Mas apesar de muito se falar em benefícios ambientais, é de extrema importância considerar na avaliação de produtos reciclados, além das características físicas do material, o risco à saúde dos usuários do novo material e dos próprios trabalhadores da indústria recicladora, devido à lixiviação de frações solúveis ou até mesmo à evaporação de frações voláteis, pois de acordo com essas características é possível determinar as melhores estratégias de manejo e produção de produtos oriundos do lodo gerado.

Em Recife por exemplo, foram realizados estudos para determinar as características do lodo de ETEs nas estações de Mangueira, Vila São João, Recife, Cabo e Cabo de Santo Agostinho. Neste estudo, constatouse que os resíduos gerados nas ETEs avaliadas, tanto no tratamento preliminar e no primário (sólidos grosseiros e areia), como a escuma dos reatores UASB, estavam dispostos nos terrenos das próprias estações, ou enviados a aterros sanitários para disposição, o que indica que a quantidade de logo gerado sem nenhum tipo de aproveitamento é enorme e que o potencial de utilização por industrias de diversos setores é uma alternativa ambientalmente adequada (SILVA, 2001).

Situação semelhante ocorria com os lodos provenientes do tratamento secundário, que após estabilizados, eram dispostos nos terrenos das estações ou levados por terceiros para serem utilizados como fertilizante na agricultura (SILVA, 2001). Ou seja, a população já tinha conhecimento do potencial de utilização dos resíduos gerados pelas estações de tratamento de esgoto, entretanto o fato de coletar estes resíduos sem nenhum tratamento prévio pode provocar desequilíbrios ambientais imensuráveis e ainda causar doenças aos moradores destas regiões (PEREIRA et al., 2017).

No trabalho foi constatado, por meio de análises de componentes principais, que os lodos de ETEs, apresentam elevados teores de alumínio, ferro, sódio, cálcio e cobre e que estes valores são preocupantes no que tange a utilização deste lodo para a agricultura. Contudo, a mesma pesquisa revelou que os metais pesados ficaram abaixo dos limites admissíveis, exceto com relação ao teor de cobre da ETE Cabo.

Nos lodos das ETEs de Mangueira, Vila São João e Recife, que apresentam reatores UASB, Silva (2001) constatou que os teores de sólidos totais voláteis e sólidos suspensos voláteis ficaram abaixo dos valores encontrados em outras ETEs com o mesmo sistema de funcionamento, e justifica esse resultado baseado no tipo de rede de coleta utilizada no estudo, pois o método adotado apresenta resultados que indicam uma quantidade significativa de areia e pobre retenção nos desarenadores existentes.

As concentrações de alumínio e de manganês nos lodos anaeróbios apresentaram valores superiores aos encontrados em outras ETEs. E os resultados dos lodos de UASB em leitos de secagem mostraram que eles se apresentam com boas características para rápida desidratação, em menos de 4 semanas e com bom potencial em termos de nutrientes. Silva (2001) ainda indica que os resultados obtidos necessitam complementações no tocante as suas características, entretanto, afirma que o potencial de utilização do lodo 
das ETEs avaliadas para uso agrícola é bastante promissor. No entanto, recomenda-se um prévio tratamento do lodo na forma de vermicompostagem antes de seu uso.

Por conta do apresentado, é possível entender que existe uma demanda de estudos mais aprofundados e a necessidade de caracterizar adequadamente os lodos provenientes das ETEs da zona metropolitana de Recife. Pois a partir de estudos dessa magnitude será possível determinar usos alternativos e seguros para os lodos da região, bem como promover a geração de renda pela utilização destes resíduos, principalmente na construção civil.

\section{CONCLUSÕES}

Esta revisão bibliográfica demonstrou que para a determinação de possíveis usos de lodos provenientes de ETE's é necessário, em primeiro lugar, realizar a caracterização do lodo que se pretende trabalhar, com a finalidade de conhecer suas propriedades, aptidões e dificuldades. Outro fator importante para deliberação de possíveis usos de lodos de ETE's é a determinação da melhor dosagem de lodo a ser utilizada como insumo para garantir a qualidade e durabilidade necessária ao produto final e a realização de ensaios tecnológicos que garantam a qualidade do uso, mas estes valores são variáveis e somente podem ser indicados mediante a caracterização dos lodos.

Conclui-se que a reutilização do lodo de esgoto após o tratamento adequado pode apresentar diversos benefícios ecológicos que justificam os custos do seu tratamento. E no que se refere ao ramo da construção civil, este resíduo apresenta uma vasta gama de possibilidades de aplicação, sendo indicado para a produção de cimento, argamassa, concreto, tijolos e telhas, bem como contribuir na melhoria das características estruturais de pavimentos. Destaca-se, entretanto, a utilização do lodo como substituto ao cimento, visto que é mais interessante do ponto de vista econômico para obras de pavimentação de concreto já que este tipo de obra usa elevadas quantidades de concreto empregadas em grandes extensões, promovendo, desta forma, maiores benefícios econômicos e potencialmente melhores resultados no âmbito ambiental.

Destaca-se ainda o potencial do estado de Pernambuco para o desenvolvimento desta atividade, principalmente a cidade do Recife, que além de possuir matéria-prima em abundância, que por vezes costuma ser descartada de forma inadequada. Ainda possui mercado consumidor aquecido, uma vez que o setor da construção civil na região apresenta elevada demanda. Diante disto, este trabalho pode ser visto como um instrumento para o desenvolvimento de novas pesquisas nesta temática para a região.

\section{REFERÊNCIAS}

ANDRADE, C.; MYNRINE, V.; DA SILVA, D. A.; SOARES MAYER, S. L.; SIMETTI, R.; MARCHIORI, F.. Composite for building from industrials waste. Matéria, Rio de Janeiro, v.21, n.2, p.321-329, 2016. DOI: http://doi.org/10.1590/S1517707620160002.0031

ARAGÃO, J.. Introdução aos estudos quantitativos utilizados em pesquisas científicas. Revista Práxis, v.3, n.6, 2013. DOI: http://doi.org/10.25119/praxis-3-6-566
AREIAS, I. O. R.; VIEIRA, C. M. F.; ST MANHÃES, R.; INTORNE, A. C.. Incorporação de lodo da estação de tratamento de esgoto (ETE) em cerâmica vermelha. Cerâmica, v.63, n.367, p.343-349, 2018. DOI: http://dx.doi.org/10.1590/0366$\underline{69132017633672004}$

AZEVEDO, A. R. G.; ALEXANDRE, J.; ZANELATO, E. B.; MARVILA, M. T.. Influence of incorporation of glass waste on 
the rheological properties of adhesive mortar. Construction and Building Materials, v.148, p.359-368, 2017. DOI: https://doi.org/10.1016/i.conbuildmat.2017.04.208

BAUER, M. W.; GASKELL, G.. Pesquisa qualitativa com texto, imagem e som: um manual prático. Recife: Vozes Limitada, 2017.

BETTIOL, W.; CAMARGO, O. A.. Impacto ambiental do uso agrícola do lodo de esgoto. Jaguariúna: Embrapa Meio Ambiente, 2000.

CAMPODONIO JUNIOR, A. C. E.; SOARES, S. V.; CASAGRANDE, M. D. H.. A produção científica brasileira sobre contabilidade tributária em periódicos e eventos no período de 1989-2011. Revista Contabilidade e Controladoria, v.6, n.1, 2014. DOI: http://dx.doi.org/10.5380/rcc.v6i1.32234

CAVALCANTI, M. M.; PIRES SOBRINHO, C. W.. Patologias Em Pavimentos de Concreto: Método ICP de Avaliação. Revista de Engenharia e Pesquisa Aplicada, v.4, n.1, 2019.

COSTA, F. M. S.. Estudo da viabilidade da utilização de cinza de lodo de esgoto como adição em argamassa de cimento Portland. Dissertação (Mestrado em Engenharia Civil) Universidade Federal do Rio Grande do Norte, Natal, 2014.

DUTRA, R. S.; AQUINO, R. C.; CAMPOS, L. F. A.; MACEDO, D. A.; FERREIRA, H. S.; MEDEIROS, F. K.. Adição de resíduo de lodo da indústria têxtil na produção de blocos cerâmicos de vedação. Revista Eletrônica de Materiais e Processos, v.10, n.1, p.29-35, 2015.

FONSECA, T. D. S; RIBEIRO JUNIOR, L. U.. Avaliação da viabilidade de implantação técnica e econômica de uma usina de reciclagem de resíduos sólidos da construção civil em Itajubá/MG. Revista Brasileira de Energias Renováveis, v.7, n.1, 2018

DOI: http://dx.doi.org/10.5380/rber.v7i1.57975

FONTES, C. M. A.; TOLEDO FILHO, R. D.; BARBOSA, M. C.. Cinza de lodo de esgoto (CLE) em concretos de alto desempenho: caracterização e aplicação. RIEM-IBRACON Structures and Materials Journal, v.9, n.6, 2016.

GASPARIM, J. C.. Viabilidade do aproveitamento de resíduo de tratamento de esgotos na construção civil. Dissertação (Mestrado) - Faculdade de Engenharia Civil, Campinas, 2013.

GODOY, L. C.. A logística na destinação do lodo de esgoto. Revista Científica on-line-Tecnologia, Gestão e Humanismo, v.2, n.1, 2013.

KUMMROW, F.; MARTINS, R. S.; LELIS, C. M.; RECH, C. M.; DA MATTA, M. E.; UMBUZEIRO, G. A.. Caracterização da Mutagenicidade de extratos aquosos e orgânicos de lodos tratados de cinco estações de tratamento de esgoto (ETE) localizadas no Estado de São Paulo. Revista Intertox de Toxicologia, Risco Ambiental e Sociedade, v.3, n.3, 2015. DOI: http://doi.org/10.22280/revintervol3ed3.58

LESSA, G. T.. Contribuição ao estudo da viabilidade da utilização do lodo de estação de tratamento biológico de esgoto misto na construção civil. Dissertação de mestrado (Mestrado Profissionalizante em Engenharia Civil) Universidade Federal do Rio Grande do Sul, Porto Alegre, 2005.
LUCENA, L. C.; JUCA, J. F. T.; SOARES, J. B.; BARROSO, S. H. A.; PORTELA, M. G.. Caracterização e avaliação do potencial de uso lodo de ETE e ETA em pavimentação. Engenharia Agrícola, v.36, n.1, p.166-178, 2016. DOI: http://doi.org/10.1590/1809-4430-Eng.Agric.v36n1p166$\underline{178 / 2016}$

LUCENA, L. C. L.; MARINHO FILHO, P. G. T.; PORTELA, M. G.. Monitoramento de parâmetros físicos e ambientais de camadas de solo estabilizadas com lodo de ETA e de ETE. Revista em Agronegócio e Meio Ambiente, v.10, n.3, p.873-890, 2017. DOI: http://doi.org/10.17765/21769168.2017v10n3p873-890

MACEDO, J. R.; SOUZA, M. D.; REICHARDT, K.; BACCHI, O. O. S.. Atributos físicos e hídricos em solo tratado com lodo de esgoto. In: BETTIOL, W.; CAMARGO, O. A.. Lodo de esgoto: impactos ambientais na agricultura. Jaguariúna: Embrapa Meio Ambiente, 2006. p.193-206.

MATOS, A. C. M.; ISEWAKI, N. T.. Alternativa de aplicação de lodo de estação de tratamento de esgoto em cobertura de aterros sanitários. In: CONGRESSO MINEIRO DE ENGENHARIAS E ARQUITETURA. Anais. Belo Horizonte, CEMEA, 2017.

MATOS, J. P. C.; DIAZ, T. C. D. S. B.. Gerenciamento de Resíduos Sólidos e a Aplicação da Logística Reversa no Segmento da Construção Civil. Revista Multidisciplinar e de Psicologia, v.13, n.43, p.784-807, 2019. DOI: http://doi.org/10.14295/idonline.v13i43.1516

MEDEIROS, S. A.. Incorporação de lodo de tanque séptico como matéria prima de uma mistura asfáltica. Dissertação (Mestrado em Engenharia) - Universidade Federal do Rio Grande do Norte, Natal, 2006.

MELLER, J. G.; MAIA, L. T.; MONTEDO, O. R. K.; ZANLORENZI H. M.; SOMMER, S. M.. Avaliação da potencialidade de resíduos gerados pela indústria de papel e celulose como materiais alternativos para a indústria cimenteira. In: FÓRUM INTERNACIONAL DE RESÍDUOS SÓLIDOS, 8. Anais. Porto Alegre, 2017.

MOREIRA, S. F.; SANTOS, S. D. O.; SARDINHA, A. S.; JÚNIOR, A. P.. ETE sludge as an alternative to soil recovery in degraded areas. Brazilian Applied Science Review, v.3, n.3, p.1564-1585, 2019. DOI: https://doi.org/10.34115/basrv3n3-006

OLIVEIRA, D. D.; ALMEIDA, E. S.; CARDOSO, L. S.; VIANA, J. D.. Produção de Blocos de Concreto Empregando Efluente Tratado por Lodos Ativados e por Lagoas de Estabilização. Revista Virtual de Química, v.8, n.4, p.10541066, 2016. DOI: http://doi.org/10.5935/1984$\underline{6835.20160075}$

OLIVEIRA, R. L.. Viabilidade do lodo de esgoto na agricultura. Exatas \& Engenharia, v.7, n.17, 2017. DOI: https://doi.org/10.25242/885X7172017898

PÁDUA, E. M. M.. Metodologia da pesquisa: abordagem teórico-prática. Campinas: Papirus, 2019.

PEREIRA, A. C. A.; GARCIA, M. L.. Disposição de lodo de ETE de indústria alimentícia no solo: efeitos na água 
subterrânea. Geociências, v.36, n.2, p.275-283, 2017.

PIRES, G. T.; GERALDO, R. H.; ZECHINATTI, V. H.; GONÇALVES, R. R. V.; GOMES, M. A. F.; VALENTE, A. M. M. P.. Adição de lodo de esgoto da ETE do município de Jaguariúna em tijolos cerâmicos: estudo de viabilidade. Revista Intellectus, Jaguariúna, v.8, n.22, p.143158, 2012.

QUEIROZ, H. F.; URZEDO, V. A. P. S. I.. Estudo da eficiência do lodo acumulado na ETA (estação de tratamento de água) como agregado não-convencional na produção de concreto. Monografia (Bacharelado em Engenharia Civil) Faculdade Aldete Maria Alves, Iturama, 2019.

RAMIREZ, K. G.. Viabilidade do aproveitamento de resíduo de estação de tratamento de água (ETA) na confecção de concretos. Dissertação (Mestrado) - Universidade Federal do Paraná, Curitiba, 2015.

REBOUÇAS, A. C; BRAGA, B.; TUNDISI, J. G.. Águas Doces no Brasil: Capital Ecológico, uso e conservação. São Paulo: Escrituras, 2017.

RODRIGUES, L. P.; HOLANDA, J. N. F.. Influence of the incorporation of water treatment plant (WTP) sludge on the technological properties of soil-cement bricks. Cerâmica, v.59, n.352, p.551-556, 2013. DOI: http://doi.org/10.1590/S0366-69132013000400010

ROSA, A. P.; CHERNICHARO, C. A. L.; MELO, G. C. B.. Contribuição para o aproveitamento energético do lodo de ETEs em processos térmicos. Revista DAE, n.198, p.55-62, 2015. DOI: http://doi.org/10.4322/dae.2014.140

SILVA, A. M. R. B.. Caracterização e avaliação do potencial de uso de lodos de estações de tratamento de esgoto doméstico da região Metropolitana do Recife. Dissertação (Mestrado em Engenharia Civil) - Universidade Federal de Pernambuco, Recife, 2001.

SILVA, J. E.; RESCK, D. V. S.; SHARMA, R. D.. Alternativa agronômica para o biossólido: a experiência de Brasília. In: BETTIOL, W.; CAMARGO, O. A.. Impacto ambiental do uso agrícola do lodo de esgoto. Jaguariúna: Embrapa Meio Ambiente, 2000. p.143-152.

SILVA, J. M.; VIER, L. C.; ROSSI, C. T.; SANTOS, R. R.; RODRIGUES, M. F.. Alternativas de destinação e reuso ambientalmente corretos e economicamente viáveis para o lodo das ETEs no estado do Rio Grande do Sul. Revista
Gestão e Desenvolvimento em Contexto, v.5, n.1, p.66-69, 2017.

SILVA, P. B.; BEZERRA, V. S.; GREGO, A.; SOUZA, L. H. A.. A pedagogia de projetos no ensino de química - O caminho das águas na Região Metropolitana do Recife: dos mananciais ao reaproveitamento dos esgotos. Química nova na escola, v. 29, p. 14,2008

SILVA, W. R.; POAGUE, K. I. H. M.; NUNES, J. C. S.. Estudo de viabilidade econômica do aproveitamento comercial de areia retida no tratamento preliminar da ETE Onça/MG. The Journal of Engineering and Exact Sciences, v.4, n.4, p.04450449, 2018.

DOI: http://doi.org/10.18540/jcecv|4iss4pp0445-0449

SILVEIRA, M. M.; FORMAGINI, S.; PINTO, J. R.; LAZAROTTO, E. F.. Argamassas produzidas com cinzas de lodo de estação de tratamento de esgoto em substituição parcial ao cimento Portland. In: ENCONTRO NACIONAL SOBRE APROVEITAMENTO DE RESÍDUOS NA CONSTRUÇÃO. Anais. Feira de Santana, 2009. p.14.

SIQUEIRA JR., B.. Água e estudo de reaproveitamento na indústria de cerâmica vermelha. Dissertação (Mestrado em Engenharia Mecânica) - Universidade Federal do Pernambuco, Recife, 2011.

SOUZA, M. A. P.; KACHUBA, D.. Novas interpretações para o consumo de massa no Brasil: uma análise sob a ótica dos planos econômicos. Percurso Acadêmico, p.329-352, 2015. DOI: http://doi.org/10.5752/P.2236-0603.2015v0n0p329$\underline{352}$

TAY, J. H.; SHOW, K. Y.; HONG, S. Y.. Potential Reuse of Wastewater Sludge for Innovative Aplications in Construction Industry. Bulletin of the College of Engineering, n.86, p.103-112, 2002.

TEIXEIRA, S. R.. Caracterização de argilas usadas para produção de cerâmica vermelha e estudo das alterações nas suas propriedades pela adição de resíduos. Tese (Doutorado em Livre Docência em Física) - Universidade Estadual Paulista 'Julio de Mesquita Filho', 2006.

VISENTIN, R.; MATEUS, C. M. D. A.; ESPERANCINI, M. S. T.; BOAS, R. L. V.; CRUZ, C. V.. Compostagem de lodo de esgoto em Botucatu: avaliação preliminar de custos. In: FÓRUM INTERNACIONAL DE RESÍDUOS SÓLIDOS. Anais. Porto Alegre, 2017.

A CBPC - Companhia Brasileira de Produção Científica (CNPJ: 11.221.422/0001-03) detém os direitos materiais desta publicação. Os direitos referem-se à publicação do trabalho em qualquer parte do mundo, incluindo os direitos às renovações, expansões e disseminações da contribuição, bem como outros direitos subsidiários. Todos os trabalhos publicados eletronicamente poderão posteriormente ser publicados em coletâneas impressas sob coordenação da Sustenere Publishing, da Companhia Brasileira de Produção Científica e seus parceiros autorizados. Os (as) autores (as) preservam os direitos autorais, mas não têm permissão para a publicação da contribuição em outro meio, impresso ou digital, em português ou em tradução. 